\title{
Kinetic Evidence for Near Irreversible Nonionic Micellar Entrapment of $N$-(2'-Methoxyphenyl)phthalimide (1) under the Typical Alkaline Reaction Conditions
}

\author{
M. Niyaz Khan, Yoke-Leng Sim, and Azhar Ariffin \\ Department of Chemistry, Faculty of Science, University of Malaya, 50603 Kuala Lumpur, Malaysia \\ Correspondence should be addressed to M. Niyaz Khan; niyaz@um.edu.my
}

Received 7 November 2013; Accepted 19 December 2013; Published 16 January 2014

Academic Editors: J. Gebler and S.-P. Ju

Copyright (c) 2014 M. Niyaz Khan et al. This is an open access article distributed under the Creative Commons Attribution License, which permits unrestricted use, distribution, and reproduction in any medium, provided the original work is properly cited.

\begin{abstract}
The values of pseudo-first-order rate constants $\left(k_{\text {obs }}\right)$ for alkaline hydrolysis of 1 , obtained at $1.0 \mathrm{mM} \mathrm{NaOH}$ and within $\left[\mathrm{C}_{m} \mathrm{E}_{n}\right]_{\mathrm{T}}$ (total concentration of $\mathrm{C}_{m} \mathrm{E}_{n}$ ) range of 3.0-5.0 mM for $\mathrm{C}_{12} \mathrm{E}_{23}$ and 10-20 mM for $\mathrm{C}_{18} \mathrm{E}_{20}$, fail to obey pseudophase micellar (PM) model. The values of the fraction of near irreversible $\mathrm{C}_{m} \mathrm{E}_{n}$ micellar trapped 1 molecules $\left(F_{\text {IT1 }}\right)$ vary in the range $\sim 0-0.75$ for $\mathrm{C}_{12} \mathrm{E}_{23}$ and $\sim 0-0.83$ for $\mathrm{C}_{18} \mathrm{E}_{20}$ under such conditions. The values of $F_{\mathrm{IT1}}$ become 1.0 at $\geq 10 \mathrm{mM} \mathrm{C}_{12} \mathrm{E}_{23}$ and $50 \mathrm{mM} \mathrm{C}_{18} \mathrm{E}_{20}$. Kinetic analysis of the observed data at $\geq 10 \mathrm{mM} \mathrm{C}_{12} \mathrm{E}_{23}$ shows near irreversible micellar entrapment of 1 molecules under such conditions.
\end{abstract}

\section{Introduction}

The 2-state Hartley model of micelle (i.e., hydrophilic headgroup/palisade/Stern layer, and hydrophobic core) of 1936 is still under extensive use [1]. However, relatively recent studies involving kinetic and spectrometric probes strongly favor the multistate model of micelle [2-6]. The unusual effects of pure $\mathrm{C}_{12} \mathrm{E}_{23}$ and mixed CTABr- $\mathrm{C}_{12} \mathrm{E}_{23}$ micelles on the acid-base behavior of phenyl salicylate were observed in 1999 [7]. In order to gain a better and clear understanding of this unusual finding, we started studying such effects on the rate of alkaline hydrolysis of esters and imides under variety of reaction kinetic conditions. This includes the use of reaction kinetic probe molecules of different structural features in the presence of pure $\mathrm{C}_{m} \mathrm{E}_{n}(m / n=12 / 23,16 / 20$, $18 / 20$, and 16/10) and mixed $\mathrm{C}_{m} \mathrm{E}_{n}$-CTABr micelles [8-12]. The unusual and unexpected observations of these studies are as follows. (i) The decrease of hydroxide ions from the neighborhood of micellized reaction kinetic probe molecules with the increase of $R\left(=\left[\mathrm{C}_{m} \mathrm{E}_{n}\right]_{\mathrm{T}} /[\mathrm{NaOH}]\right.$ at a constant value of $[\mathrm{NaOH}]$ ) at a typical value of $R_{t}$ which represents a typical value of $\left[\mathrm{C}_{m} \mathrm{E}_{n}\right]_{\mathrm{T}} /[\mathrm{NaOH}]$ above which $k_{\mathrm{obs}}$ versus $\left[\mathrm{C}_{m} \mathrm{E}_{n}\right]_{\mathrm{T}}$ data fails to obey PM model. (ii) The observed data $\left(k_{\mathrm{obs}}\right.$ versus $\left[\mathrm{C}_{m} \mathrm{E}_{n}\right]_{\mathrm{T}}$ ) obey PM model at $R \leq R_{t}$. (iii) The rate of hydrolysis of reaction kinetic probe molecules almost ceased when $R \gg R_{t}$. (iv) The unusual observation of (iii) could be detected with $\mathrm{C}_{12} \mathrm{E}_{23}, \mathrm{C}_{16} \mathrm{E}_{10}$, and $\mathrm{C}_{18} \mathrm{E}_{20}$ but not with $\mathrm{C}_{16} \mathrm{E}_{20}$ under approximately similar conditions.

Under the typical reaction conditions of earlier studies where $R \gg R_{t}$ and the rate of reaction which could not be detected within the reaction period of more than $\sim 24 \mathrm{~h}$, the possibility of whether the cessation of the rate of reaction was due to complete or near irreversible micellar binding of one of the reactants of a bimolecular reaction has not been explored. Although the meaning of "near irreversible binding" is a subjective one, we arbitrarily consider the transition of a reversible binding to near irreversible binding if the value of $k_{\mathrm{obs}}$ changes from $\sim 10^{-4} \mathrm{~s}^{-1}$ (under the reversible binding condition) to $\sim 10^{-8} \mathrm{~s}^{-1}$ (under the near irreversible binding condition). The present work was initiated with an aim to find out if the cessation of the rate of reaction at $\geq 0.01 \mathrm{M}$ $\mathrm{C}_{12} \mathrm{E}_{23}$ was caused by the near irreversible micellar binding of $\mathbf{1}$. The observed results and their probable explanations are described in this paper.

\section{Materials and Methods}

2.1. Materials. Synthesis of $\mathbf{1}$ (Figure 1) has been reported earlier [14], and all the other chemicals used were commercial 
TABLE 1: The values of $k_{\mathrm{obs}}, \delta_{\mathrm{ap}}$, and $A_{0}$ for alkaline hydrolysis of $\mathbf{1}$ in the presence of $\mathrm{C}_{12} \mathrm{E}_{23}{ }^{\mathrm{a}}$.

\begin{tabular}{|c|c|c|c|c|c|c|}
\hline $\begin{array}{l}{\left[\mathrm{C}_{12} \mathrm{E}_{23}\right]_{\mathrm{T}}} \\
\mathrm{M}\end{array}$ & $\begin{array}{c}10^{4} k_{\text {obs }} \\
\mathrm{s}^{-1}\end{array}$ & $\begin{array}{c}\begin{array}{c}\delta_{\mathrm{ap}} \\
\mathrm{M}^{-1} \mathrm{~cm}^{-1}\end{array} \\
\end{array}$ & $10^{2} A_{0}$ & $Y_{\mathrm{obs}}^{\mathrm{b}}$ & $Y_{\text {cald }}{ }^{\mathrm{c}}$ & $F_{\text {ITT1 }}{ }^{\mathrm{d}}$ \\
\hline 0.003 & $30.5 \pm 1.4^{\mathrm{e}}$ & $3012 \pm 53^{\mathrm{e}}$ & $24.8 \pm 0.5^{\mathrm{e}}$ & 11.1 & 3.76 & 0 \\
\hline 0.0034 & $19.3 \pm 1.0$ & $2691 \pm 48$ & $24.8 \pm 0.5$ & 17.6 & 4.13 & 0.13 \\
\hline 0.0038 & $8.31 \pm 1.89$ & $2280 \pm 158$ & $26.3 \pm 1.3$ & 40.9 & 4.50 & 0.26 \\
\hline 0.0042 & $2.21 \pm 0.47$ & $1657 \pm 129$ & $25.9 \pm 0.8$ & 154 & 4.87 & 0.46 \\
\hline 0.005 & $0.273 \pm 0.019$ & $770 \pm 22$ & $23.9 \pm 0.1$ & 1245 & 5.61 & 0.75 \\
\hline 0.01 & & & & & & \\
\hline 0.02 & & & & & & \\
\hline 0.03 & & & & & & \\
\hline 0.05 & & & & & & \\
\hline
\end{tabular}

${ }^{\mathrm{a}}\left[\mathbf{1}_{0}\right]=0.1 \mathrm{mM},[\mathrm{NaOH}]=1.0 \mathrm{mM}, \lambda=290 \mathrm{~nm}, T=35^{\circ} \mathrm{C}$, and the aqueous reaction mixture contained $2 \% \mathrm{v} / \mathrm{v} \mathrm{CH}{ }_{3} \mathrm{CN} .{ }^{\mathrm{b}} Y_{\mathrm{obs}}=k_{W} / k_{\mathrm{obs}}$, where $k_{W}=k_{\mathrm{obs}}$ $\left(=340 \times 10^{-4} \mathrm{~s}^{-1}[13]\right)$ at [micelles] $=0 .{ }^{\mathrm{c}}$ Calculated from the relationship: $Y_{\text {cald }}=\phi+\Psi\left[\mathrm{C}_{12} \mathrm{E}_{23}\right]$ with $\phi=0.982$ and $\Psi=925 \mathrm{M}^{-1}$ [13]. ${ }^{\mathrm{d}}$ The values of $F_{\mathrm{IT} 1}$ were calculated from (2) with $\delta_{\text {ap }}$ avg $=3090 \mathrm{M}^{-1} \mathrm{~cm}^{-1}$. ${ }^{\mathrm{e}}$ Error limits are standard deviations. ${ }^{\mathrm{f}}$ No change in $A_{\text {obs }}$ until $t=600 \mathrm{~h}$, where $A_{\text {obs }}=0.246 .{ }^{\mathrm{g}} \mathrm{No}$ change in $A_{\text {obs }}$ until $t=1083 \mathrm{~h}$, where $A_{\mathrm{obs}}=0.261 .{ }^{\mathrm{h}}$ No change in $A_{\mathrm{obs}}$ until $t=1085 \mathrm{~h}$, where $A_{\mathrm{obs}}=0.271$. ${ }^{\mathrm{i}}$ No change in $A_{\mathrm{obs}}$ until $t=1102 \mathrm{~h}$, where $A_{\text {obs }}=0.286$.<smiles>[X]N1C(=O)c2ccccc2C1=O</smiles>

Imide<smiles>[R]NC(=O)c1ccccc1C(=O)[O-]</smiles>

Phthalamate
1, $\mathrm{Z}=2-\mathrm{CH}_{3} \mathrm{OC}_{6} \mathrm{H}_{4}$
3, $\mathrm{Z}=\mathrm{CH}_{2} \mathrm{C}_{6} \mathrm{H}_{5}$
2, $\mathrm{Z}=2-\mathrm{CH}_{3} \mathrm{OC}_{6} \mathrm{H}_{4}$
4, $\mathrm{Z}=\mathrm{CH}_{2} \mathrm{C}_{6} \mathrm{H}_{5}$

Figure 1: Molecular structures of compounds 1, 2, 3 and 4.

products of the highest available purity. Stock solutions of $\mathbf{1}$ ( $5 \mathrm{mM}$ and $10 \mathrm{mM}$ ) were prepared in acetonitrile. Throughout the text, the symbol $[\mathrm{X}]_{\mathrm{T}}$ represents the total concentration of $\mathrm{X}$.

2.2. Kinetic Measurements. The rate of nonionic micellarmediated alkaline hydrolysis of $\mathbf{1}$ was studied spectrophotometrically at $35^{\circ} \mathrm{C}$ by monitoring the appearance of hydrolysis product, $N$-( $2^{\prime}$-methoxyphenyl)phthalamate (2) of $\mathbf{1}$ at $290 \mathrm{~nm}$ as a function of reaction time, $t$. The observed data, absorbance $\left(A_{\mathrm{obs}}\right)$ versus $t$, obeyed

$$
A_{\mathrm{obs}}=\delta_{\mathrm{ap}}\left[\mathbf{1}_{0}\right]\left[1-\exp \left(-k_{\mathrm{obs}} t\right)\right]+A_{0},
$$

where $k_{\text {obs }}$ and $\delta_{\text {ap }}$ represent pseudo-first-order rate constants for alkaline hydrolysis of $\mathbf{1}$ and molar absorptivity of reaction mixture, respectively, and $\left[\mathbf{1}_{0}\right]$ is the initial concentration of $\mathbf{1}$ and $A_{0}=A_{\text {obs }}$ at $t=0$. The details of the product characterization are described elsewhere [13].

\section{Results}

3.1. Effects of $\left[C_{12} E_{23}\right]_{T}$ and $\left[C_{18} E_{20}\right]_{T}$ on Pseudo-First-Order Rate Constants $\left(k_{\text {obs }}\right)$ for Hydrolysis of 1 at $1.0 \mathrm{mM} \mathrm{NaOH}$ and $35^{\circ} \mathrm{C}$. The rate of alkaline hydrolysis of 1 was studied within $\left[\mathrm{C}_{12} \mathrm{E}_{23}\right]_{\mathrm{T}}$ range of 3-50 mM, but the absorbance of the reaction mixtures within $\left[\mathrm{C}_{12} \mathrm{E}_{23}\right]_{\mathrm{T}}$ range of $10-50 \mathrm{mM}$ remained unchanged in the reaction time $(t)$ range of $\sim 15 \mathrm{~s}-$ $623 \mathrm{~h}$. However, the observed data $\left(A_{\mathrm{obs}}\right.$ versus $\left.t\right)$, obtained within $\left[\mathrm{C}_{12} \mathrm{E}_{23}\right]_{\mathrm{T}}$ range of $3-5 \mathrm{mM}$, were found to fit to (1). The least-squares calculated values of $k_{\mathrm{obs}}, \delta_{\mathrm{ap}}$, and $A_{0}$, obtained under such conditions, are shown in Table 1. Similarly, the kinetic runs for the rate of alkaline hydrolysis of 1 were carried out within $\left[\mathrm{C}_{18} \mathrm{E}_{20}\right]_{\mathrm{T}}$ range of $10-50 \mathrm{mM}$. But the absorbance of the reaction mixture at $50 \mathrm{mM} \mathrm{C}_{18} \mathrm{E}_{20}$ remained unchanged within the $t$ range of $\sim 15 \mathrm{~s}-\sim 260 \mathrm{~h}$. The calculated values of $k_{\mathrm{obs}}, \delta_{\mathrm{ap}}$, and $A_{0}$ for the kinetic runs carried out within $\left[\mathrm{C}_{18} \mathrm{E}_{20}\right]_{\mathrm{T}}$ range of $10-20 \mathrm{mM}$ are shown in Table 2.

\section{Discussion}

4.1. Evidence for the Near Irreversible $C_{12} E_{23}$ Micellar Binding of 1 under the Typical Reaction Conditions. It can be easily shown from the derivation of (1) that $\delta_{\mathrm{ap}}=\delta_{2}-\delta_{1}$, where $\delta_{2}$ represents molar absorptivity of 2 (Figure 1). The values of $\delta_{1}$ and $\delta_{2}$, at $290 \mathrm{~nm}$, are 2480 and $5570 \mathrm{M}^{-1} \mathrm{~cm}^{-1}$ [15], respectively, in aqueous alkaline solvent containing $2 \% \mathrm{v} / \mathrm{v}$ $\mathrm{CH}_{3} \mathrm{CN}$. The values of $\delta_{1}$ are independent of $\left[\mathrm{C}_{m} \mathrm{E}_{n}\right]_{\mathrm{T}}[13]$. The values of $\delta_{\mathrm{ap}}$ [13] reveal that the values of $\delta_{2}$ are also independent of $\left[\mathrm{C}_{m} \mathrm{E}_{n}\right]_{\mathrm{T}}$ within its range of $0.0-3.0 \mathrm{mM}$ for $\mathrm{C}_{16} \mathrm{E}_{20}$ and $\mathrm{C}_{12} \mathrm{E}_{23}$ as well as $0.0-5.0 \mathrm{mM}$ for $\mathrm{C}_{18} \mathrm{E}_{20}$. However, the values of $\delta_{2}$ show a nonlinear increase from 5570 to $8450 \mathrm{M}^{-1} \mathrm{~cm}^{-1}$ at $290 \mathrm{~nm}$ with the increase in the content of $\mathrm{CH}_{3} \mathrm{CN}$ from 2 to $80 \% \mathrm{v} / \mathrm{v}$ in mixed $\mathrm{H}_{2} \mathrm{O}$ $\mathrm{CH}_{3} \mathrm{CN}$ solvent [15]. Thus, the decrease in $\delta_{\text {ap }}$ with increase 
TABLE 2: The values of $k_{\mathrm{obs}}, \delta_{\mathrm{ap}}$, and $A_{0}$ for alkaline hydrolysis of $\mathbf{1}$ in the presence of $\mathrm{C}_{18} \mathrm{E}_{20}{ }^{\mathrm{a}}$.

\begin{tabular}{|c|c|c|c|c|c|c|}
\hline $\begin{array}{l}{\left[\mathrm{C}_{18} \mathrm{E}_{20}\right]_{\mathrm{T}}} \\
\mathrm{M}\end{array}$ & $\begin{array}{c}10^{4} k_{\text {obs }} \\
\mathrm{s}^{-1}\end{array}$ & $\begin{array}{c}\delta_{\mathrm{ap}} \\
\mathrm{M}^{-1} \mathrm{~s}^{-1} \\
\end{array}$ & $10^{2} A_{0}$ & $Y_{\mathrm{obs}}^{\mathrm{b}}$ & $Y_{\text {cald }}{ }^{\mathrm{c}}$ & $F_{\text {IT } 1}{ }^{\mathrm{d}}$ \\
\hline 0.01 & $41.9 \pm 0.3^{\mathrm{e}}$ & $3233 \pm 9^{e}$ & $27.2 \pm 0.0^{\mathrm{e}}$ & 7.92 & 7.89 & 0 \\
\hline 0.012 & $15.7 \pm 0.5$ & $2637 \pm 30$ & $28.0 \pm 0.1$ & 21.1 & 9.27 & 0.17 \\
\hline 0.014 & $11.6 \pm 0.4$ & $2459 \pm 31$ & $28.6 \pm 0.2$ & 28.6 & 10.6 & 0.23 \\
\hline 0.016 & $7.11 \pm 0.24$ & $1239 \pm 15$ & $29.1 \pm 0.1$ & 46.7 & 12.0 & 0.61 \\
\hline 0.018 & $5.89 \pm 0.38$ & $898 \pm 19$ & $29.5 \pm 0.1$ & 56.4 & 13.4 & 0.72 \\
\hline 0.02 & $2.17 \pm 0.22$ & $546 \pm 26$ & $29.9 \pm 0.1$ & 153 & 14.8 & 0.83 \\
\hline 0.05 & $\mathrm{f}$ & & & & & \\
\hline
\end{tabular}

${ }^{\mathrm{a}}\left[\mathbf{1}_{0}\right]=0.1 \mathrm{mM},[\mathrm{NaOH}]=1.0 \mathrm{mM}, \lambda=290 \mathrm{~nm}, T=35^{\circ} \mathrm{C}$, and the aqueous reaction mixture contained $2 \% \mathrm{v} / \mathrm{v} \mathrm{CH}_{3} \mathrm{CN}$. Footnotes ${ }^{\mathrm{b}}$ and ${ }^{\mathrm{c}}$ represent respective footnotes ${ }^{\mathrm{b}}$ and ${ }^{\mathrm{c}}$ of Table 1 with replacement of $\left[\mathrm{C}_{12} \mathrm{E}_{23}\right]$ by $\left[\mathrm{C}_{18} \mathrm{E}_{20}\right]$ as well as $k_{W}=338 \times 10^{-4} \mathrm{~s}^{-1}, \phi=0.998$, and $\Psi=689 \mathrm{M}^{-1}$ [13]. ${ }^{\mathrm{d}}$ The values of $F_{\mathrm{IT} 1}$ were calculated from (2) with $\delta_{\text {ap }}{ }^{\text {avg }}=3190 \mathrm{M}^{-1} \mathrm{~cm}^{-1}$. ${ }^{\mathrm{e}}$ Error limits are standard deviations. ${ }^{\mathrm{f}}$ Spectrophotometrically undetectable reaction within the reaction period of $\sim 260 \mathrm{~h}$, where $A_{\mathrm{obs}}=0.392$.

in $\left[\mathrm{C}_{m} \mathrm{E}_{n}\right]_{\mathrm{T}}$ (Tables 1 and 2) rules out the possibility of $\mathrm{C}_{m} \mathrm{E}_{n}$ $(m / n=16 / 20,12 / 23$, and 18/20) micellar binding of 2 in a micellar environment of lower concentration of water compared with water concentration of bulk aqueous phase. These observations show that the effects of $\left[\mathrm{C}_{m} \mathrm{E}_{n}\right]_{\mathrm{T}}$ on $\delta_{1}$ and $\delta_{2}$ cannot explain the observed decrease in $\delta_{\text {ap }}$ with increase in $\left[\mathrm{C}_{m} \mathrm{E}_{n}\right]_{\mathrm{T}}$ at the typical values of $\left[\mathrm{C}_{m} \mathrm{E}_{n}\right]_{\mathrm{T}}$ (Tables 1 and 2 ). Thus, the most plausible reason for such decrease in $\delta_{\mathrm{ap}}$ is due to near irreversible micellar trapping of unreacted $\mathbf{1}$. Under such circumstances, the observed data $\left(k_{\text {obs }}\right.$ versus $\left[\mathrm{C}_{m} \mathrm{E}_{n}\right]_{\mathrm{T}}$ ) listed in Tables 1 and 2 cannot be expected to obey pseudophase micellar model (PM).

It can be shown that the fraction of near irreversibly $\mathrm{C}_{m} \mathrm{E}_{n}$ micellar trapped $\mathbf{1}$ at $t=\infty\left(F_{\mathrm{IT} 1}\right)$ may be given as

$$
F_{\mathrm{IT} 1}=1-\left(\frac{\delta_{\mathrm{ap}}}{\delta_{\mathrm{ap}}^{\mathrm{avg}}}\right)
$$

where $\delta_{\text {ap }}$ and $\delta_{\text {ap }}{ }^{\text {avg }}$ represent apparent molar absorptivity of the reaction mixture at $F_{\mathrm{IT} 1} \neq 0$ and $F_{\mathrm{IT} 1}=0$, respectively. The derivation of (2) involves the assumption that the absorbance due to medium microturbidity remains unchanged within the reaction period of $t=0$ to $t=\infty$. The values of $F_{\text {IT1 } 1}$ were calculated from (2) at different $\left[\mathrm{C}_{m} \mathrm{E}_{n}\right]_{\mathrm{T}}$ and these values are summarized in Table 1 for $\mathrm{C}_{12} \mathrm{E}_{23}$ and Table 2 for $\mathrm{C}_{18} \mathrm{E}_{20}$. It is evident from the calculated values of $F_{\text {IT1 }}$ that the value of $\left[\mathrm{C}_{m} \mathrm{E}_{n}\right]_{\mathrm{T}} /[\mathrm{NaOH}](=R)$ is nearly 3.6-fold larger for $\mathrm{C}_{18} \mathrm{E}_{20}$ than that for $\mathrm{C}_{12} \mathrm{E}_{23}$ to result in nearly same value of $F_{\mathrm{IT} 1}$, while the value of $F_{\text {IT1 } 1}$ remains zero even at $R=170$ for $\mathrm{C}_{16} \mathrm{E}_{20}$ [13]. The typical value of $R\left(=R_{t}\right)$, at which $F_{\mathrm{IT1}}=0.13$, is 3.4 for $\mathrm{C}_{12} \mathrm{E}_{23}$. Similarly, the value of $R_{t}$, at which $F_{\mathrm{IT} 1}=$ 0.17 , is 12.0 for $\mathrm{C}_{18} \mathrm{E}_{20}$. The values of $F_{\mathrm{IT} 1}$ and $F_{\mathrm{IT} 3}$ are $\sim 0$ [13] and 0.60 [11], respectively, at $R=170$ for $\mathrm{C}_{16} \mathrm{E}_{20}$ micelles which reveal that the structural features of imide substrates (1 and 3) (Figure 1) affect the values of $F_{\text {IT1 }}$ at a fixed value of $R$. It is interesting and amazing to note that the difference of only 2 methylene $\left(\mathrm{CH}_{2}\right)$ groups between $\mathrm{C}_{18} \mathrm{E}_{20}$ and $\mathrm{C}_{16} \mathrm{E}_{20}$ has so much different effects on $F_{\mathrm{IT} 1}$.

If micellar entrapment of unreacted 1 , as shown by $F_{\text {IT1 }}$ values in Tables 1 and 2, is indeed an irreversible or near irreversible process, then the values of $A_{\text {obs }}$ at $t \geq 10$ halflives (Reaction time $t$ at $\sim 10$ half-lives is equivalent to $t_{\infty}$ because more than $99.9 \%$ reaction is progressed during the reaction period of 10 half-lives and therefore, at $t_{\infty}, A_{\mathrm{obs}}=$ $A_{\infty}$ ) should remain essentially unchanged with the increase in $t$ at $t=t_{\infty}$ or at $t$, where $A_{\mathrm{obs}}=A_{\infty}$. In order to test this conclusion, the kinetic reaction mixtures at $0.01,0.02,0.03$, and $0.05 \mathrm{M} \mathrm{C}_{12} \mathrm{E}_{23}$ were left at $35^{\circ} \mathrm{C}$ for the reaction period of $\sim 1.10 \times 10^{3} \mathrm{~h}$ and the values of $A_{\mathrm{obs}}$, during these reaction periods, remained essentially unchanged (Table 1 ).

It is apparent from Tables 1 and 2 that the values of $F_{\text {IT1 }}$ increase nonlinearly with the increase of $R$ at a typical value of $R\left(=R_{t}\right)$ and the values of $F_{\text {IT1 } 1}$ appear to become 1 at $R \geq 10$ for $\mathrm{C}_{12} \mathrm{E}_{23}$ (Table 1 ) and at $R=50$ for $\mathrm{C}_{18} \mathrm{E}_{20}$ (Table 2). If the reversible and near irreversible nonionic micellar binding of $\mathbf{1}$ is a function of $R$, then the change of inequality from $R>R_{t}$ to $R<R_{t}$, by sudden external addition of known amount of $\mathrm{NaOH}$ to the reaction mixture at $t>t_{\infty}$, must cause near irreversible bound $\mathbf{1}_{\mathrm{M}}$ molecules to become reversible bound $\mathbf{1}_{\mathrm{M}}$ molecules. Consequently, the rate of appearance of product (2) of this reaction mixture would follow (1) and the value of $k_{\mathrm{obs}}$ may then be compared with $k_{\text {obs }}$ obtained by carrying out another kinetic run by the use of authentic sample of $\mathbf{1}$ under essentially similar experimental conditions. Such an attempt is described as follows.

To $3.0 \mathrm{~cm}^{3}$ of the reaction mixture containing $0.1 \mathrm{mM} \mathbf{1}$, $1.0 \mathrm{mM} \mathrm{NaOH}$, and $10 \mathrm{mM} \mathrm{C}_{12} \mathrm{E}_{23}$ (i.e., $R=10$ ), $0.02 \mathrm{~cm}^{3}$ of 1.0 $\mathrm{M} \mathrm{NaOH}$ was added at $t=432 \mathrm{~h}$. The absorbance change of the resulting reaction mixture was quickly monitored spectrophotometrically at $290 \mathrm{~nm}$ as a function of reaction time $(t)$. The observed data $\left(A_{\text {obs }}\right.$ versus $\left.t\right)$ were found to fit to (1) and the least-squares calculated values of kinetic parameters $k_{\mathrm{obs}}, \delta_{\mathrm{ap}}$, and $A_{0}$ are summarized in Table 3. Similar kinetic runs were carried out at different $t(\geq 600 \mathrm{~h})$ and $\left[\mathrm{C}_{12} \mathrm{E}_{23}\right]_{\mathrm{T}}(=0.02,0.03$, and $0.05 \mathrm{M})$ and the values of $k_{\text {obs }}$, $\delta_{\text {ap }}$, and $A_{0}$, obtained under these conditions, are also shown in Table 3.

A few kinetic runs were carried out using authentic sample of $\mathbf{1}$ freshly prepared at $35^{\circ} \mathrm{C}, 0.1 \mathrm{mM} \mathbf{1}$, different values of $\left[\mathrm{C}_{12} \mathrm{E}_{23}\right]_{\mathrm{T}}$ (ranging from 10 to $50 \mathrm{mM}$ ) and $[\mathrm{NaOH}]$ (ranging from 4.2 to $30.0 \mathrm{mM}$ ). The spectrophotometrically observed 
TABLE 3: Values of $k_{\mathrm{obs}}, \delta_{\mathrm{ap}}$, and $A_{0}$ calculated from (1) for alkaline hydrolysis of 1 in the presence of $\mathrm{C}_{12} \mathrm{E}_{23}$ micelles ${ }^{\mathrm{a}}$.

\begin{tabular}{|c|c|c|c|c|c|c|c|c|c|}
\hline $\begin{array}{l}10^{3}\left[\mathrm{C}_{12} \mathrm{E}_{23}\right]_{\mathrm{T}} \\
\mathrm{M}\end{array}$ & $\begin{array}{c}10^{3}[\mathrm{NaOH}] \\
\mathrm{M}\end{array}$ & $\begin{array}{c}10^{3} k_{\text {obs }} \\
\mathrm{s}^{-1} \\
\end{array}$ & $\begin{array}{c}\delta_{\mathrm{ap}} \\
\mathrm{M}^{-1} \mathrm{~cm}^{-1} \\
\end{array}$ & $10^{3} A_{0}$ & $\begin{array}{c}k_{\mathrm{OH}}^{\mathrm{b}} \\
\mathrm{M}^{-1} \mathrm{~s}^{-1} \\
\end{array}$ & $F_{\mathrm{IT} 1}{ }^{\mathrm{c}}$ & $R^{\mathrm{d}}$ & $\begin{array}{l}t^{\mathrm{e}} \\
\mathrm{h}\end{array}$ & $\begin{array}{c}10^{8} k_{1}{ }^{\mathrm{f}} \\
\mathrm{s}^{-1}\end{array}$ \\
\hline $9.9^{g}$ & 7.6 & $64.2 \pm 0.8^{\mathrm{h}}$ & $2088 \pm 25^{\mathrm{h}}$ & $256 \pm 3^{\mathrm{h}}$ & 8.45 & 0.68 & 1.30 & 432 & 25 \\
\hline 9.9 & 7.6 & $66.1 \pm 1.1$ & $1691 \pm 32$ & $267 \pm 3$ & 8.70 & 0.55 & 1.30 & 600 & 27 \\
\hline $10.0^{\mathrm{i}}$ & 7.6 & $67.8 \pm 0.5$ & $3293 \pm 25$ & $260 \pm 3$ & 8.92 & & 1.32 & & \\
\hline 19.8 & 11.0 & $44.4 \pm 0.5$ & $2127 \pm 19$ & $303 \pm 2$ & 4.04 & 0.70 & 1.82 & 623 & 16 \\
\hline 19.8 & 11.0 & $35.0 \pm 0.2$ & $1564 \pm 7$ & $314 \pm 1$ & 3.18 & 0.51 & 1.82 & 1083 & 18 \\
\hline $20.0^{\mathrm{i}}$ & 11.0 & $51.2 \pm 0.2$ & $3344 \pm 13$ & $282 \pm 1$ & 4.65 & & 1.82 & & \\
\hline 29.5 & 17.4 & $69.9 \pm 0.9$ & $2714 \pm 45$ & $297 \pm 5$ & 4.02 & 0.89 & 1.70 & 600 & 5.5 \\
\hline 29.5 & 17.4 & $70.3 \pm 0.3$ & $2271 \pm 92$ & $310 \pm 9$ & 4.04 & 0.74 & 1.70 & 1085 & 7.6 \\
\hline $30.0^{\mathrm{i}}$ & 17.0 & $64.8 \pm 0.3$ & $3325 \pm 16$ & $331 \pm 2$ & 3.81 & & 1.76 & & \\
\hline 48.5 & 30.0 & $86.3 \pm 1.5$ & $3302 \pm 93$ & $291 \pm 9$ & 2.88 & 1.08 & 1.62 & 622 & - \\
\hline 48.5 & 30.0 & $88.1 \pm 1.8$ & $2789 \pm 89$ & $324 \pm 9$ & 2.94 & 0.91 & 1.62 & 1102 & 2.3 \\
\hline $48.5^{\mathrm{i}}$ & 30.0 & $78.6 \pm 2.5$ & $3365 \pm 129$ & $406 \pm 13$ & 2.62 & & 1.62 & & \\
\hline
\end{tabular}

${ }^{\mathrm{a}}\left[\mathbf{1}_{0}\right]=0.1 \mathrm{mM}, \lambda=290 \mathrm{~nm}, T=35^{\circ} \mathrm{C}$, and the aqueous reaction mixture contained $2 \% \mathrm{v} / \mathrm{v} \mathrm{CH}_{3} \mathrm{CN} .{ }^{\mathrm{b}} k_{\mathrm{OH}}=k_{\mathrm{obs}}[\mathrm{NaOH}] .{ }^{\mathrm{c}} F_{\mathrm{IT} 1}=\delta_{\mathrm{ap}} / \delta_{\mathrm{ap}}{ }^{\text {avg }}$ with $\delta_{\text {ap }}^{\text {avg }}=3058 \mathrm{M}^{-1} \mathrm{~cm}^{-1} \cdot{ }^{\mathrm{d}} R=\left[\mathrm{C}_{12} \mathrm{E}_{23}\right]_{\mathrm{T}} /[\mathrm{NaOH}] .{ }^{\mathrm{e}} t$ is reaction time $\left(t \geq t_{\infty}\right)$ where the kinetic reaction mixture was used for micellar entrapment experiment. ${ }^{\mathrm{f}}$ Calculated from the relationship: $k_{1}=(1 / t) \ln \left(1 / F_{\mathrm{IT1}}\right) .{ }^{\mathrm{g}}$ Value of $\left[\mathrm{C}_{12} \mathrm{E}_{23}\right]_{\mathrm{T}}$ after external addition of $[\mathrm{NaOH}] .{ }^{\mathrm{h}}$ Error limits are standard deviations. ${ }^{\mathrm{i}}$ Reaction mixture for kinetic run was freshly prepared, where $\delta_{\text {ap }}=\delta_{\text {ap }}{ }^{\text {avg }}$.

data for these kinetic runs followed strictly (1) as evident from the standard deviations associated with the calculated kinetic parameters $k_{\mathrm{obs}}, \delta_{\mathrm{ap}}$, and $A_{0}$ (Table 3$)$. The values of $k_{\mathrm{OH}}\left(=k_{\mathrm{obs}} /[\mathrm{NaOH}]\right)$ are $>4$-fold smaller than $k_{\mathrm{OH}}(=$ $36 \mathrm{M}^{-1} \mathrm{~s}^{-1}$ ) [15] obtained under similar kinetic conditions in the absence of micelles. These results may be attributed to merely nonionic micellar inhibitory effect (the fraction of micellized 1, i.e., $\mathbf{1}_{\mathrm{M}}$, under such conditions, is $>90 \%$, where $\left.K_{S}=925 \mathrm{M}^{-1}[13]\right)$.

The values of $k_{\mathrm{obs}}$, obtained from the reaction mixtures at different $\left[\mathrm{C}_{12} \mathrm{E}_{23}\right]_{\mathrm{T}}$ and the reaction time $t$ (ranging from 432 to $1102 \mathrm{~h}$ ) at which the value of $[\mathrm{NaOH}]$ was increased from $1.0 \mathrm{mM}$ to $\geq 7.6 \mathrm{mM}$ and $\leq 30.0 \mathrm{mM}$, are comparable with the corresponding values of $k_{\mathrm{obs}}$, obtained from authentic sample of 1 (Table 3 ). These observations support the proposal of near irreversible entrapment of $\mathbf{1}$ molecules by $\mathrm{C}_{12} \mathrm{E}_{23}$ micelles at $R \gg R_{t}$. The observed values of $A_{\mathrm{obs}}$ at $t \geq 600 \mathrm{~h}$ as well as $\leq 1102 \mathrm{~h}$ and $\left[\mathrm{C}_{12} \mathrm{E}_{23}\right]_{\mathrm{T}}$ range of $10-50 \mathrm{mM}$ (Table 1) reveal that the values of $F_{\mathrm{IT} 1}$ must be nearly 1 . But the calculated values of $F_{\mathrm{IT} 1}$ at $t \approx 600 \mathrm{~h}$, as summarized in Table 3 , increase from $\sim 0.55$ to $\sim 1.0$ with the respective increase in $\left[\mathrm{C}_{12} \mathrm{E}_{23}\right]_{\mathrm{T}}$ from 10 to $50 \mathrm{mM}$. Similarly, the values of $F_{\mathrm{IT} 1}$ at $t$ range of $\approx 1083-1102 \mathrm{~h}$, shown in Table 3 , increase from 0.51 to 0.91 with the respective increase in $\left[\mathrm{C}_{12} \mathrm{E}_{23}\right]_{\mathrm{T}}$ from 20 to $50 \mathrm{mM}$. These results show that, even at the highest value of $\left[\mathrm{C}_{12} \mathrm{E}_{23}\right]_{\mathrm{T}}(=50 \mathrm{mM})$ of the present study, nearly $9 \%$ hydrolysis of 1 occurred within the reaction time $(t)$ of $1102 \mathrm{~h}$. Thus, it is apparent that there is not any absolute/complete irreversible micellar entrapment of 1 molecules-a situation encountered with usual shielding effect of the micelles. A qualitative explanation of these observations may be described as below.
In view of the earlier reports $[8,11]$ on the related reaction systems, the rate of hydrolysis of $\mathbf{1}$ at $1.0 \mathrm{mM} \mathrm{NaOH}, 35^{\circ} \mathrm{C}$, and within $\left[\mathrm{C}_{12} \mathrm{E}_{23}\right]_{\mathrm{T}}$ range of $0.01-0.05 \mathrm{M}$ may be expected to follow an irreversible consecutive reaction path:

$$
\mathbf{1}_{\mathrm{M}} \stackrel{k_{1}}{\longrightarrow} 2_{\mathrm{M}} \stackrel{k_{2}}{\longrightarrow} \mathrm{PAn}_{\mathrm{M}}+2-\mathrm{MA}_{\mathrm{M}}
$$

where PAn and 2-MA represent phthalic anhydride and 2-methoxyaniline, respectively, and subscript $M$ represents micellar pseudophase. The values of $k_{2}\left(\right.$ at $35^{\circ} \mathrm{C}$ ) are almost zero and $12 \times 10^{-4} \mathrm{~s}^{-1}$ at $1.0 \mathrm{mM} \mathrm{NaOH}$ and $49 \mathrm{mM} \mathrm{HCl}$, respectively [15]. The efficient reactivity of nonionized 2 (i.e., $2 \mathbf{H}$ ) towards the formation of PAn is primarily due to intramolecular carboxylic group-assisted cleavage of $2 \mathbf{H}$ [15]. The respective absence and presence of the formation of PAn in the aqueous cleavage of 3 at $1.0 \mathrm{mM} \mathrm{NaOH}$, $\left[\mathrm{C}_{16} \mathrm{E}_{10}\right]_{\mathrm{T}} \leq 30 \mathrm{mM}$, and at $\left[\mathrm{C}_{16} \mathrm{E}_{10}\right]_{\mathrm{T}} \geq 50 \mathrm{mM}$ have been ascribed to the consequence of the effects of $\left[\mathrm{C}_{16} \mathrm{E}_{10}\right]_{\mathrm{T}}$ on the $\mathrm{pH}$ of micellar environment of nonionized 4 (Figure 1) [11]. Spectrophotometric evidence revealed the fact that the increase in $\left[\mathrm{C}_{12} \mathrm{E}_{23}\right]_{\mathrm{T}}$ at $R \gg R_{t}$ with a constant value of $[\mathrm{NaOH}]$ caused decrease in $\mathrm{pH}$ of micellar environment of micellized ionized phenyl salicylate [7, 9]. In view of this study, at $\left[\mathrm{C}_{12} \mathrm{E}_{23}\right]_{\mathrm{T}} \geq 10 \mathrm{mM}$, the $\mathrm{pH}$ of the micellar environment of $\mathbf{2}_{\mathrm{M}}$ dropped to a level where there was significant amount of $\mathbf{2} \mathbf{H}$ which caused kinetically detectable occurrence of $k_{2}$ - step (see (3)) within $\left[\mathrm{C}_{12} \mathrm{E}_{23}\right]_{\mathrm{T}}$ range of $10-$ $30 \mathrm{mM}$.

The respective values of $\delta_{1}, \delta_{2}, \delta_{2 \mathrm{H}}$, and $\delta_{\mathrm{PAn}}$ (with $\delta_{\mathrm{X}}$ representing molar absorptivity of $\mathrm{X}$ ) at $290 \mathrm{~nm}$ are $\sim 2420$ [13], 5570-8450, 4545-7490, and 2300-2000 $\mathrm{M}^{-1} \mathrm{~cm}^{-1}$ [11] within $\mathrm{CH}_{3} \mathrm{CN}$ content range of $2-80 \% \mathrm{v} / \mathrm{v}$ in mixed aqueous solvent. Close similarity of the values of $\delta_{1}$ and $\delta_{\text {PAn }}$ coupled 
with significantly higher values of $\delta_{2}$ or $\delta_{2 \mathrm{H}}$ compared with those of $\delta_{1}$ and $\delta_{\mathrm{PAn}}$ reveal that $k_{2}>k_{1}$. These observations explain the observed constancy of $A_{\text {obs }}$ within reaction time $(t)$ ranging from $\sim 15 \mathrm{~s}$ to $\leq 1102 \mathrm{~h}$ at $10-50 \mathrm{mM} \mathrm{C}_{12} \mathrm{E}_{23}$ (Table 1). The rough and approximate values of $k_{1}$ were obtained from the relationship: $k_{1}=(1 / t) \ln \left(1 / F_{\text {IT1 }}\right)$ and such calculated values of $k_{1}$ at two different $t$ and three $\left[\mathrm{C}_{12} \mathrm{E}_{23}\right]_{\mathrm{T}}$ $(10,20$, and $30 \mathrm{mM})$ are shown in Table 3. It is evident from these results that the values of $k_{1}$ at two different $t$ and at a constant $\left[\mathrm{C}_{12} \mathrm{E}_{23}\right]_{\mathrm{T}}$ are comparable within the limits of experimental uncertainties. But the values of $k_{1}$ decrease almost nonlinearly with the increasing values of $\left[\mathrm{C}_{12} \mathrm{E}_{23}\right]_{\mathrm{T}}$. Thus, the values of $k_{1}$ became almost zero at $50 \mathrm{mM} \mathrm{C}_{12} \mathrm{E}_{23}$ and as a consequence only $\sim 9 \%$ conversion of $\mathbf{1}$ to 2 could occur at $t=1102 \mathrm{~h}$ (Table 3 ). The values of $k_{1}$ decreased from $\sim 26 \times 10^{-8}$ to $2.3 \times 10^{-8} \mathrm{~s}^{-1}$ with the increase in $\left[\mathrm{C}_{12} \mathrm{E}_{23}\right]_{\mathrm{T}}$ from 10 to $50 \mathrm{mM}$. The values of $k_{1}$ were found to decrease by $\sim 3$-fold, while the values of $k_{2}$ remained unchanged with the increase of $\left[\mathrm{C}_{16} \mathrm{E}_{10}\right]_{\mathrm{T}}$ from 50 to $88 \mathrm{mM}$ in the aqueous cleavage of 3 [11]. Although the calculated values of $k_{1}$ are not very reliable because they are derived from only either two or one data point(s), these values of $k_{1}$ appear to be plausible for the reason that the value of $k_{1}$ at $\mathrm{pH} \sim 3.5$, in mixed aqueous solvent containing $2 \% \mathrm{v} / \mathrm{v} \mathrm{CH}_{3} \mathrm{CN}$, is $67 \times 10^{-8} \mathrm{~s}^{-1}$ [16]. Under such typical conditions, the value of $k_{2}$ is $120 \times 10^{-5} \mathrm{~s}^{-1}$ and it decreases from $120 \times 10^{-5}$ to $6.6 \times 10^{-5} \mathrm{~s}^{-1}$ with increase in $\mathrm{CH}_{3} \mathrm{CN}$ content from 2 to $82 \% \mathrm{v} / \mathrm{v}$ [15].

The values of $k_{\text {obs }}$ and $k_{1}$ show a nonlinear decrease with the increase of $\left[\mathrm{C}_{12} \mathrm{E}_{23}\right]_{\mathrm{T}}$ within its range of $1.0 \times$ $10^{-6}-0.05 \mathrm{M}$ (Tables 1 and 3 ). The value of $k_{\mathrm{M}}$ (=rate constant for hydrolysis of $\mathbf{1}$ in the micellar pseudophase) remained kinetically undetectable under such conditions. The observed data failed to obey the pseudophase micellar (PM) model at $>1.4 \mathrm{mM} \mathrm{C}_{12} \mathrm{E}_{23}$ because the values of micellar binding constant of $\mathbf{1}\left(K_{S}\right)$ increase significantly $\left(\sim 10^{3}\right.$-fold $)$ with the increase in $\left[\mathrm{C}_{12} \mathrm{E}_{23}\right]_{\mathrm{T}}$ from 1.4 to $50 \mathrm{mM}$ at $1.0 \mathrm{mM} \mathrm{NaOH}$ (Tables 1 and 3). Similar but not identical observations have been obtained in $\mathrm{CTABr}$-(cetyltrimethylammonium bromide-) mediated $\mathrm{pH}-$ independent hydrolysis of $\mathrm{N}$-(2-hydroxyphenyl)phthalimide [17]. The scenario exhibited by these observations supports the multicompartmental model of micelle $[2,18,19]$ and it may best be represented by Scheme 1 , where $n_{1} \mathbf{l}_{M}$ molecules are in equilibrium with $\mathrm{n} \mathbf{1}_{\mathrm{W}}$ molecules and equilibrium or micellar binding constant $K_{S}{ }^{1}$ at $R \leq 2$ and $[\mathrm{NaOH}]=$ $1.0 \mathrm{mM}$. Similarly, $\mathrm{n}_{2} \mathbf{1}_{\mathrm{M}}, \mathrm{n}_{3} \mathbf{1}_{\mathrm{M}}, \mathrm{n}_{4} \mathbf{1}_{\mathrm{M}}$, and $\mathrm{n}_{5} \mathbf{1}_{\mathrm{M}}$ molecules are in equilibrium with $n \mathbf{1}_{\mathrm{W}}$ molecules and equilibrium constants $K_{S}{ }^{2}, K_{S}{ }^{3}, K_{S}{ }^{4}$, and $K_{S}{ }^{5}$ at respective $R=10,20$, 30 , and 50 and a constant $1.0 \mathrm{mM} \mathrm{NaOH}$.

\section{Conclusions}

The new and notable aspects of the present paper are the experimentally determined pseudo-first-order rate constants $\left(k_{1} \equiv k_{\text {obs }}\right)$ of the order of $10^{-7}-10^{-8} \mathrm{~s}^{-1}$ for the hydrolysis of 1 within the $R$ range of $10-50$, where $R=\left[\mathrm{C}_{12} \mathrm{E}_{23}\right]_{\mathrm{T}} /[\mathrm{NaOH}]$, with a constant value of $[\mathrm{NaOH}](=1.0 \mathrm{mM})$. These values of $k_{1}$ are $>10^{5}$-fold smaller than $k_{\mathrm{obs}}$ at $R \leq 1.4$,

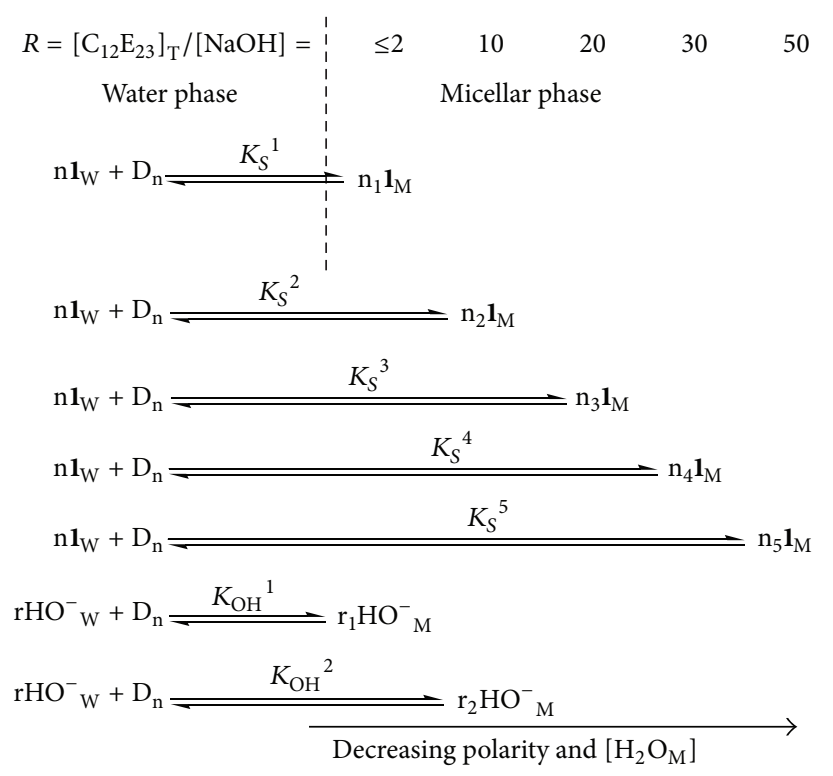

SCHEME 1

where pseudophase micellar $(\mathrm{PM})$ reveals that $k_{\mathrm{M}} \approx 0$ and $K_{S}=925 \mathrm{M}^{-1}$ [13]. The kinetic data of this paper show that the half-lives of alkaline hydrolysis of 1 at $1.0 \mathrm{mM}$ $\mathrm{NaOH}$ and $35^{\circ} \mathrm{C}$ vary in the order $24 \mathrm{~s}, 6 \mathrm{~min}, 7 \mathrm{~h}, 31,47$, 122 , and 349 days at $R=0.2,3.4,5.0,10,20,30$, and 50, respectively. Such quantitative information may be useful for designing nonionic micelles as the carrier of drug molecules containing imide functionality. These kinetic data also provide quantitative but indirect evidence for the multistate model of micelle suggested, to the best of our knowledge, in only a few reports $[2-6,18,19]$.

\section{Conflict of Interests}

The authors declare that there is no conflict of interests regarding the publication of this paper.

\section{Acknowledgments}

The authors thank the Ministry of Higher Education (MO$\mathrm{HE}$ ) and University of Malaya (UM) for financial assistance through research Grants UM.C/HIR/MOHE/SC/07.

\section{References}

[1] F. M. Menger, "The structure of micelles," Accounts of Chemical Research, vol. 12, no. 4, pp. 111-117, 1979.

[2] D. M. Davies, N. D. Gillitt, and P. M. Paradis, "Catalysis and inhibition of the iodide reduction of peracids by surfactants: partitioning of reactants, product and transition state between aqueous and micellar pseudophases," Journal of the Chemical Society, Perkin Transactions 2, vol. 4, pp. 659-666, 1996.

[3] A. Mishra, R. K. Behera, P. K. Behera, B. K. Mishra, and G. B. Behera, "Cyanines during the 1990s: a review," Chemical Reviews, vol. 100, no. 6, pp. 1973-2011, 2000. 
[4] M. N. Khan and E. Ismail, "An empirical approach to study the occurrence of ion exchange in the alkaline hydrolysis of phthalimide in the presence of cationic micelles and inert salts," Journal of Molecular Liquids, vol. 136, no. 1-2, pp. 54-63, 2007.

[5] A. Laschewsky, "Polymerized micelles with compartments," Current Opinion in Colloid and Interface Science, vol. 8, no. 3, pp. 274-281, 2003.

[6] F. Sterpone, C. Pierleoni, G. Briganti, and M. Marchi, "Molecular dynamics study of temperature dehydration of a $\mathrm{C}_{12} \mathrm{E}_{6}$ spherical micelle," Langmuir, vol. 20, no. 11, pp. 4311-4314, 2004.

[7] M. N. Khan, Z. Arifin, M. R. Yusoff, and E. Ismail, "Effects of nonionic, cationic, and mixed nonionic-cationic surfactants on the acid-base behavior of phenyl salicylate," Journal of Colloid and Interface Science, vol. 220, no. 2, pp. 474-476, 1999.

[8] M. N. Khan and E. Ismail, "Effects of non-ionic and mixed cationic-non-ionic micelles on the rate of alkaline hydrolysis of phthalimide," Journal of Physical Organic Chemistry, vol. 15, no. 7, pp. 374-384, 2002.

[9] M. N. Khan, E. Ismail, and M. R. Yusoff, "Effects of pure nonionic and mixed non-ionic-cationic surfactants on the rates of hydrolysis of phenyl salicylate and phenyl benzoate in alkaline medium," Journal of Physical Organic Chemistry, vol. 14, no. 10, pp. 669-676, 2001.

[10] M. N. Khan and E. Ismail, "Effects of non-ionic and mixed non-ionic-cationic micelles on the rate of aqueous cleavages of phenyl benzoate and phenyl salicylate in alkaline medium," Journal of Physical Organic Chemistry, vol. 17, no. 5, pp. 376-386, 2004.

[11] M.-Y. Cheong, A. Ariffin, and M. N. Khan, "Kinetic coupled with UV spectral evidence for near-irreversible nonionic micellar binding of $N$-benzylphthalimide under the typical reaction conditions-an observation against a major assumption of the pseudophase micellar model," Journal of Physical Chemistry B, vol. 111, no. 42, pp. 12185-12194, 2007.

[12] M. N. Khan and C. T. Fui, "Unusual effects of pure nonionic and mixed nonionic-cationic micelles on the rate of alkaline hydrolysis of $N$-hydroxyphthalimide," Journal of Dispersion Science and Technology, vol. 31, no. 7, pp. 909-917, 2010.

[13] Y.-L. Sim, N. S. M. Yusof, A. Ariffin, and M. N. Khan, "Effects of nonionic micelles on the rate of alkaline hydrolysis of $N-\left(2^{\prime}\right.$ methoxyphenyl)phthalimide (1): kinetic and rheometric evidence for a transition from spherical to rodlike micelles under the typical reaction conditions," Journal of Colloid and Interface Science, vol. 360, no. 1, pp. 182-188, 2011.

[14] Y.-L. Sim, A. Ariffin, and M. N. Khan, "Efficient rate enhancement due to intramolecular general base (IGB) assistance in the hydrolysis of $\mathrm{N}$-(o-hydroxyphenyl)phthalimide," The Journal of Organic Chemistry, vol. 72, no. 7, pp. 2392-2401, 2007.

[15] Y.-L. Sim, A. Ariffin, and M. N. Khan, "Intramolecular carboxylic group-assisted cleavage of $N$-(2-hydroxyphenyl)- phthalamic acid (7) and $N$-(2-methoxyphenyl)-phthalamic acid (8): absence of intramolecular general acid catalysis due to $2-\mathrm{OH}$ in 7," International Journal of Chemical Kinetics, vol. 38, no. 12, pp. 746-758, 2006.

[16] Y.-L. Sim, W. H. W. Ahmad, M. Y. Cheong, A. Ariffin, and M. N. Khan, "Kinetics and mechanism of hydrolysis of $N$-arylphthalimides," Progress in Reaction Kinetics and Mechanism, vol. 34, no. 4, pp. 347-359, 2009.
[17] M. N. Khan and M. H. R. Azri, "Effects of $[\mathrm{NaBr}]$ on the rate of intramolecular general base-assisted hydrolysis of $N$ - $\left(2^{\prime}\right.$-hydroxyphenyl)phthalimide in the presence of cationic micelles: kinetic evidence for the probable micellar structural transition," Journal of Physical Chemistry B, vol. 114, no. 24, pp. 8089-8099, 2010.

[18] G. G. Warr, T. N. Zemb, and M. Drifford, "Liquid-liquid phase separation in cationic micellar solutions," The Journal of Physical Chemistry, vol. 94, no. 7, pp. 3086-3092, 1990.

[19] Y. Geng, L. S. Romsted, and F. Menger, "Specific ion pairing and interfacial hydration as controlling factors in gemini micelle morphology. Chemical trapping studies," Journal of the American Chemical Society, vol. 128, no. 2, pp. 492-501, 2006. 

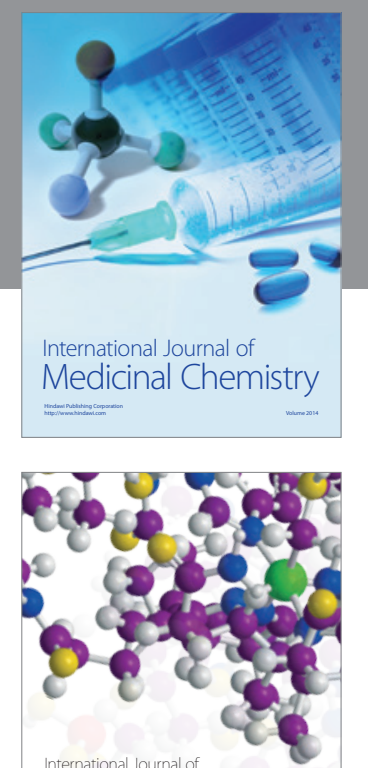

\section{Carbohydrate} Chemistry

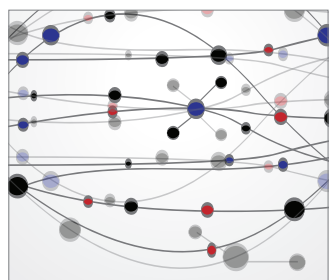

The Scientific World Journal
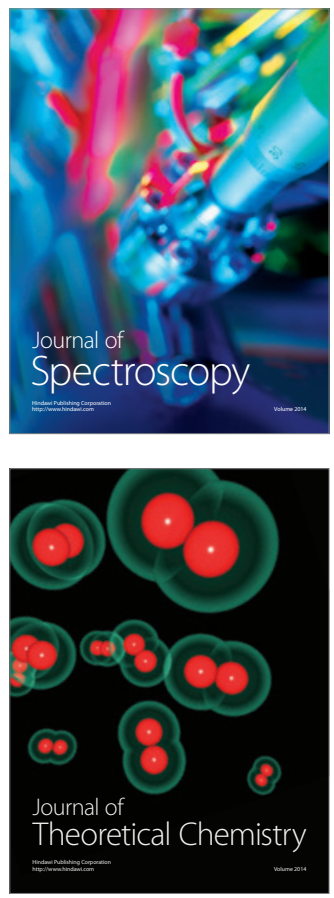
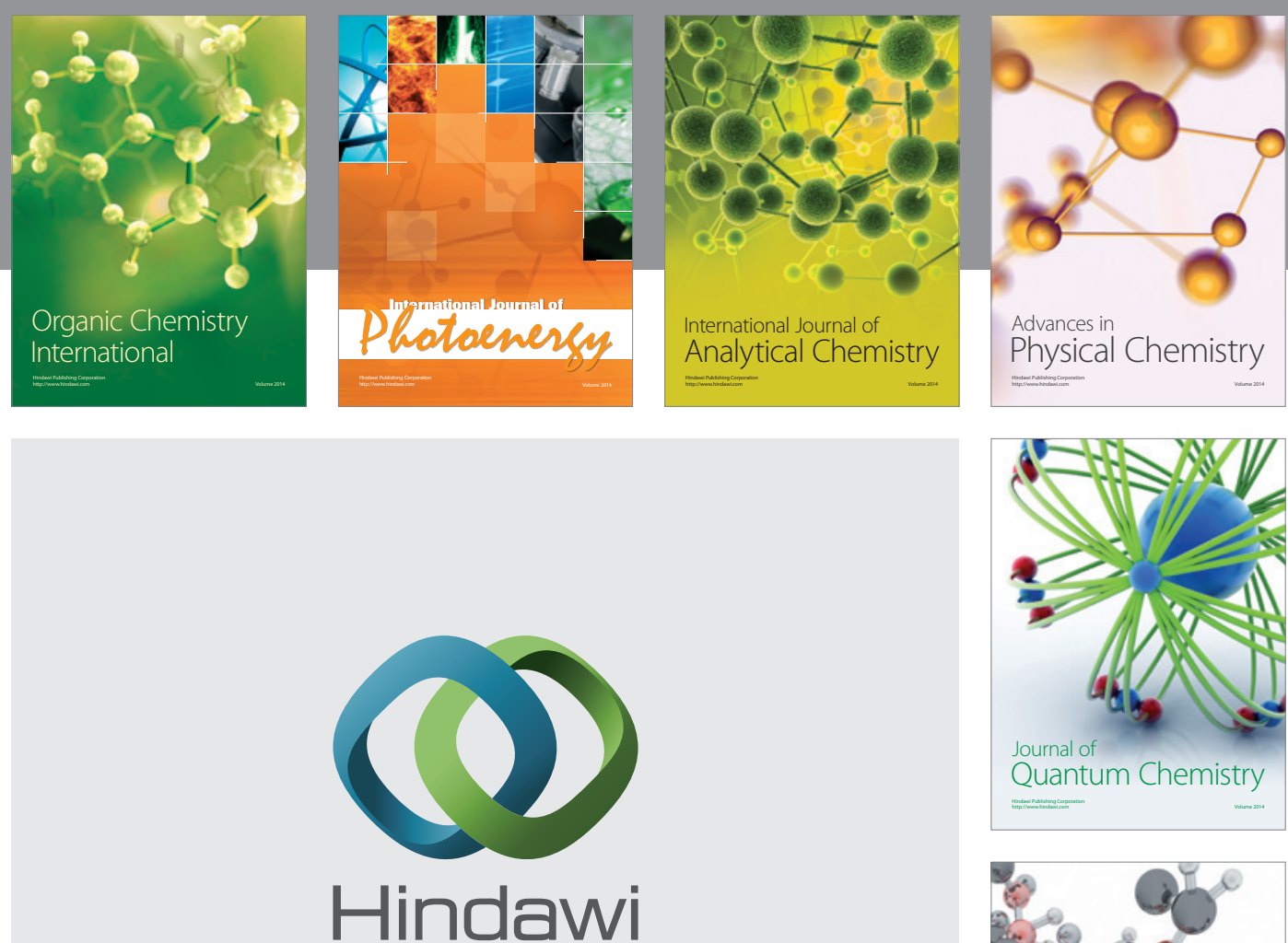

Submit your manuscripts at

http://www.hindawi.com

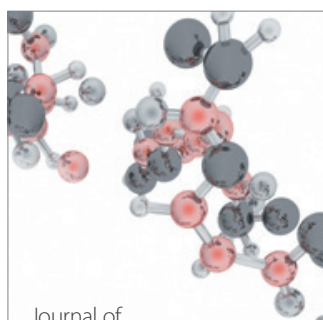

Analytical Methods

in Chemistry

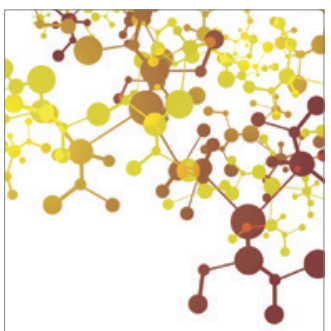

Journal of

Applied Chemistry

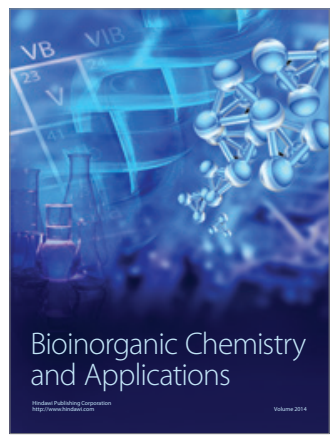

Inorganic Chemistry
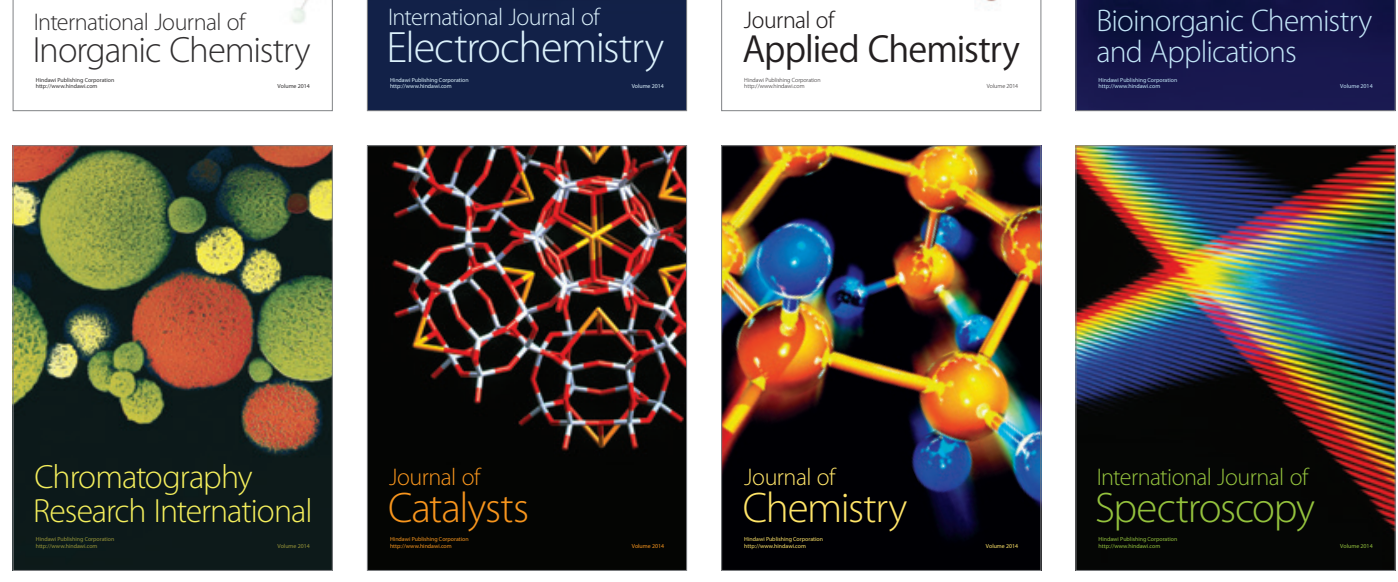